\title{
ANALISIS KOMPARATIF USAHATANI JAGUNG DAN KEDELAI DI KABUPATEN JEMBER
}

\section{ANALYSIS OF COMPARATIVE MAIZE AND SOYBEAN N DISTRICT Of JEMBER}

\author{
Yusuf Muhammad Albana ${ }^{1}$, Edy Sutiarso ${ }^{2}$, dan Nurul Fathiyah F. ${ }^{2}$ \\ 1) Mahasiswa Program Studi Agribisnis, Fakultas Pertanian, UM Jember \\ 2) Dosen Program Studi Agribisnis, Fakultas Pertanian, UM Jember \\ Alamate-mail: yusuf.albana12@gmail.com
}

\begin{abstract}
ABSTRAK
Penelitian ini bertujuan untuk mengukur dan mengidentifikasi perbedaan nilai produktivitas usahatani jagung dan kedelai, untuk mengidentifikasi faktor-faktor yang berpengaruh terhadap nilai produksi usahatani jagung dan kedelai, untuk mengukur dan mengidentifikasi perbedaan keuntungan usahatani jagung dan kedelai, untuk mengidentifikasi faktor-faktor yang berpengaruh terhadap keuntungan usahatani jagung dan kedelai, untuk mengukur dan mengidentifikasi perbedaan efisiensi penggunaan biaya usahatani jagung dan kedelai. Penelitian ini menggunakan metode survey dan komparatif dengan pemilihan daerah secara multi-stage sampling, terpilih Kecamatan Balung dan Bangsalsari, Kabupaten Jember. Pengambial sampel dilakukan secara multi-stage sampling, data diperoleh dari wawancara dengan petani dan instansi terkait. Metode analisis data menggunakan uji beda (statistik uji-z) dan analisis regresi berganda (statistik uji-t dan uji-f). Penelitian ini menyimpulkan bahwa, nilai produktivitas (lahan, tenaga kerja dan biaya produksi) jagung (Rp 18.227.753/ha; Rp 30.303/JKP; 1,49) dan kedelai (Rp12.924.009/ha; Rp 30.662/JKP; 1,37), ada perbedaan nilai produktivitas (lahan dan biaya produksi) yang signifikan pada taraf uji 1\%, Sedangkan nilai produktivitas (tenaga kerja) tidak ada perbedaan yang signifikan. Faktor-faktor yang berpengaruh nyata terhadap nilai produksi jagung dan kedelai yaitu luas lahan, nilai benih, nilai pupuk, dan tenaga kerja, sedangkan nilai pestisida dan manajerial berpengaruh tidak nyata. Usahatani (jagung dan kedelai) di Kabupaten Jember menguntungkan, yaitu sebesar (Rp 5.963.080/ha; Rp 3.422.641/ha), ada perbedaan yang signifikan pada taraf uji 1\%. Faktor nilai produksi, biaya sarana produksi, tenaga kerja dan sewa lahan berpengaruh nyata terhadap keuntungan usahatani jagung dan kedelai. Penggunaan biaya produksi usahatani jagung dan kedelai adalah efisien dengan nilai $\mathrm{R} / \mathrm{C}$ sebesar 1,49 dan 1,37 , ada perbedaan yang signifikan nilai $\mathrm{R} / \mathrm{C}$ antara usahatani jagung dan kedelai.
\end{abstract}

Kata Kunci: jagung, kedelai, keuntungan, komparatif, produktivitas.

\section{ABSTRACT}

This study aims to measure and identify differences in productivity values of corn and soybean farms, to identify factors that affect the value of corn and soybean production, to measure and identify differences in the benefits of corn and soybean farming, to identify factors that affect the profits corn and soybean farms, to measure and identify the different efficiencies of using corn and soybean farming costs. This research used survey and comparative method with multi-stage sampling, selected by Balung and Bangsalsari subdistricts, Jember District. The sample samples were conducted in random sampling, the data were obtained from interviews with farmers and related institutions. Methods of data analysis using different test (z-test statistic) and multiple regression analysis (t-test statistic 
and f-test). This research concludes that the value of productivity (land, labor and production cost) of maize ( $R p$ 18.227.753/ha, $R p$ 30.303/JKP; 1,49) and soybean (Rp12.924.009/ha; Rp 30.662/JKP; 1,37), there is a significant difference in productivity value (land and production cost) at the test level of 1\%, while the value of productivity (labor) is no significant difference. Factors that significantly affect the value of corn and soybean production are land area, seed value, fertilizer value, and labor, whereas pesticide and managerial values have no significant effect. Farming (corn and soybean) in Jember Regency is profitable, that is (Rp 5,963,080/ha, Rp 3,422,641/ha), there is a significant difference at 1\% test level. Factor of production value, production cost, labor and land rent have real effect to corn and soybean farming profit. The use of corn and soybean production cost is efficient with $R / C$ value of 1.49 and 1.37 , there is a significant difference of $R / C$ value between corn and soybean farming.

Keywords: comparative, corn, productivity, profit, soybean.

\section{PENDAHULUAN}

Pada dasarnya Indonesia telah mencanangkan pelaksanaan program swasembada kedelai sejak pertengahan tahun 1960an terus berlanjut hingga kini. Swasembada kedelai belum berhasil dicapai karena dihadapkan pada berbagai kendala dalam pelaksanaannya sebagai akibat dari: (a) rendahnya minat petani; (b) belum berkembangnya penerapan teknologi anjuran di tingkat usahatani, khususnya pemakaian benih unggul bermutu dan pemakaian pupuk berimbang; (c) meningkatnya impor kedelai karena adanya kemudahan tataniaga impor dan (d) terjadinya persaingan penggunaan sumberdaya lahan dengan komoditas lain, khususnya jagung. Dengan kondisi tersebut, kinerja pegembangan kedelai menunjukkan masih rapuhnya sistem agribisnis kedelai, sehingga tidak berkembangnya luas areal tanam dan panen serta masih rendahnya tingkat produktivitas yang dicapai dan menjadikan produksi kedelai domestik tidak mampu mencukupi kebutuhan dalam negeri (Zakaria, 2010).

Ada beberapa tinjauan teoristis yang dapat digunakan sebagai landasan berfikir dalam penelitian ini yaitu meliputi: konsep usahatani, teori produksi, fungsi produksi, teori biaya, teori keuntungan dan faktor-faktor yang mempengaruhi usahatani serta teori efisiensi biaya. Suprapto (2006) dalam hasil penelitiannya mengemukakan bahwa komoditas jagung di Jawa Timur untuk orientasi ekspor memperoleh proteksi dari pemerintah sedangkan untuk orientasi subtitusi impor dan perdagangan antar daerah tidak mendapatkan proteksi dari pemerintah. Selanjutnya Rahayu (2011) dari hasil penelitiannya mengungkapkan bahwa faktor-faktor yang berpengaruh secara nyata terhadap 
Volume 02, No 02- September 2018

ISSN: 2581-1339 (Print), ISSN: 2615-4862 (Online)

produksi usahatani kedelai yaitu luas

keuntungan usahatani kedelai. Berikut

lahan, pupuk, pestisida dan tenaga kerja,

kerangka pemikiran usahatani jagung dan sedangkan jumlah benih dan manajerial berpengaruh tidak nyata terhadap produksi usahatani kedelai. Faktor produksi, harga jual, dan biaya produksi berpengaruh signifikan terhadap

kedelai di Kabupaten Jember. Adapun kerangka pemikiran yang melandasai penelitian ini dapat dijelaskan sebagaiman yang ditunjukkan pada Gambar 1.

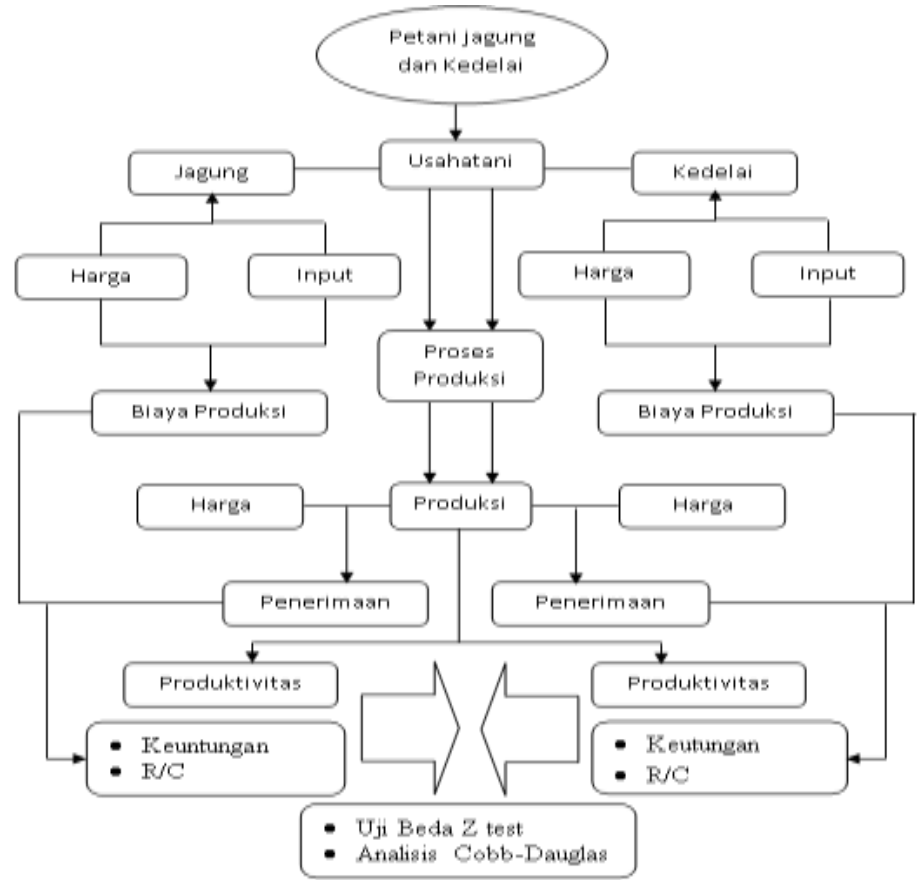

Gambar 1. Skema Kerangka Pemikiran Penelitian

Berdasarkan fakta ini, maka penelitian ini burtujuan: (1) Untuk mengukur dan mengidentifikasi perbedaan nilai produktivitas usahatani jagung dan kedelai; (2) Untuk mengidentifikasi faktor-faktor yang berpengaruh terhadap nilai produksi usahatani jagung dan kedelai; (3) Untuk mengukur dan mengidentifikasi perbedaan keuntungan usahatani jagung dan kedelai; (4) Untuk mengidentifikasi faktor-faktor yang berpengaruh terhadap keuntungan usahatani jagung dan kedelai; (5)

Untuk mengukur dan mengidentifikasi perbedaan efisiensi penggunaan biaya usahatani jagung dan kedelai.

\section{METODE PENELITIAN}

\section{Metode Penelitian dan Lokasi Penelitian}

Metode yang digunakan dalam penelitian ini adalah metode survey dan studi komparatif. Menurut Suryabrata 
(1983), metode survey merupakan cara untuk mengumpulkan data dari sejumlah unit atau individu dalam jangka waktu tertentu secara bersamaan, metode survey juga melakukan wawancara secara langsung kepada petani atau responden. Studi komparatif digunakan karena penelitian ini membandingkan nilai produktivitas, tingkat keuntungan dan efisiensi penggunaan biaya antara usahatani jagung dan kedelai. Selanjutnya daerah penelitian ditentukan secara multistage sampling dan terpilih Kecamatan Balung dan Bangsalsari Kabupaten Jember sebagai lokasi penelitian.

\section{Metode Pengambilan Sampel dan Data}

Pemilihan desa sampel dilakukan secara random sampling sebanyak 5 desa pada mesing-masing kecamatan, kemudian dipilih 6 petani jagung dan 6 petani kedelai dari masing-masing desa. Sementara dalam penelitian ini jenis data yang digunakan terdiri atas jenis data primer dan data sekunder. Data primer dikumpulkan melalui wawancara langsung dengan responden (petani jagung dan kedelai) menggunakan daftar pertanyaan yang telah dipersiapkan, Sementara data sekunder diperoleh dari instansi terkait.

\section{Metode Analisis Data}

1. Untuk menguji hipotesis digunakan pendekatan Average Physical Product (APP) dengan formulasi sebagai berikut:

di mana:

$$
A P P=\frac{T P P}{X}=\frac{Q}{X}=\frac{f(X)}{X}
$$
input

$\mathrm{APP}=$ produksi rata-rata per satuan

$\mathrm{TPP}=$ produksi total

$\mathrm{Q}=$ output atau produksi yang dihasilkan

$\mathrm{X}=$ luas lahan

2. Untuk menguji hipotesis yang kedua digunakan pendekatan analisis regresi berganda munggunakan fungsi produksi Cobb-Douglas. Hubungan antara variabel $\mathrm{X}$ dan $\mathrm{Y}$ dirumuskan sebagai berikut (Sutiarso, 2010):

$$
\begin{gathered}
\hat{Y}_{i}=\beta_{0} X_{1}^{\beta_{1}} X_{2}^{\beta_{2}} \ldots X_{i}^{\beta_{i}} e^{d D+u_{i}} \\
\hat{Y}=b_{0} X_{1}^{b_{1}} X_{2}^{b_{2}} X_{3}^{b_{3}} X_{4}^{b_{4}} X_{5}^{b_{5}} X_{6}^{b_{6}} e^{d D+u_{i}} \\
\text { di mana: } \\
\hat{Y}=\text { nilai produksi usahatani jagung } \\
\text { dan kedelai (Rp) yang ditaksir } \\
X_{1}=\text { luas lahan }\left(\mathrm{m}^{2}\right) \\
X_{2}=\text { nilai benih }(\mathrm{Rp}) \\
X_{3}=\text { nilai pupuk (Rp) } \\
X_{4}=\text { nilai pestisida (Rp) } \\
X_{5}=\text { jumlah tenaga kerja (JKP) } \\
X_{6}=\text { manajerial (th) } \\
D=\text { variabel dummy: } \\
D=1 \text { untuk jagung; } D=0 \text { untuk } \\
\text { kedelai } \\
b_{0}=\text { konstanta (intersep) } \\
b_{1}, b_{2}, \ldots, b_{6}=\text { koefisien regresi } \\
\text { variabel bebas }
\end{gathered}
$$


3. Pengujian hipotesis yang ketiga analog dengan pengujian hipotesis yang pertama, untuk mengukur besarnya keuntungan usahatani jagung dan kedelai digunakan pendekatan analisis keuntungan sebagai berikut:

$\pi=T R-T C$

$T R=P \cdot Q$

$T C=T F C+T V C$

di mana:

$\pi=$ Keuntungan $(\mathrm{Rp})$

$T R=$ Total Penerimaan $($ Total Revenue)

$T C=$ Total Biaya $($ Total Cost $)$

$P=$ Harga satuan produksi

$Q=$ Jumlah produksi $(\mathrm{kg})$

$T F C=$ Total Biaya Tetap $($ Total Fixed Cost)

$T V C=$ Total Biaya Variabel $($ Total

\section{Variabel Cost)}

4. Untuk menguji hipotesis yang keempat, digunakan pendekatan analisis regresi bergand fungsi keuntungan Cobb-Douglas. Hubungan antara variabel $\mathrm{X}$ dan $\mathrm{Y}$ secara matematik dirumuskan(Sutiarso, 2010):

$$
Y_{i}=\beta_{0} X_{1 i}^{\beta_{1}} X_{2 i}^{\beta_{2}} \ldots X_{k i}^{\beta_{k}} e^{u_{i}}
$$

Faktor-faktor yang diduga berpengaruh terhadap keuntungan adalah harga output, jumlah produksi dan biaya produksi. Secara matematis, persamaan taksiran fungsi keuntungan dengan model regresi adalah:

$$
\hat{Y}=\mathrm{b}_{0} X_{1}^{b_{1}} X_{2}^{b_{2}} X_{3}^{b_{3}} X_{4}^{b_{4}}
$$

di mana:

$\hat{Y}=$ keuntungan usahatani kedelai (Rp)

$X_{1}=$ nilai produksi $(\mathrm{Rp})$

$X_{2}=$ biaya sarana produksi $(\mathrm{Rp})$

$X_{3}=$ biaya tenaga kerja $(\mathrm{Rp})$

$X_{4}=$ biaya sewa lahan (Rp)

$b_{0}=$ konstanta

$b_{1}, b_{2}, \ldots, b_{5}=$ koefisien regresi

variabel bebas

5. Untuk menguji hipotesis yang kelima, tentang dugaan adanya perbedaan efisiensi penggunaan biaya antara usahatani jagung dan usahatani kedelai, Uji yang digunakan analog dengan pengujian hipotesis yang pertama. Untuk mengetahui efisiensi penggunaan biaya produksi digunakan pendekatan RC ratio. Formulasinya adalah sebagai berikut:

$$
R / C=\frac{\text { Total Revenue }(\mathrm{TR})}{\text { Total Cost }(\mathrm{TC})}
$$

di mana:

$\mathrm{TR}=\mathrm{Y} . \mathrm{Py}$

$\mathrm{TC}=$ Biaya Sarana Produksi + Biaya Tenaga Kerja + Biaya Lain-Lain

Kriteria Pengambilan Keputusan:

$\mathrm{R} / \mathrm{C} \leq(1+i)$, biaya produksi yang digunakan tidak efisien. $\mathrm{R} / \mathrm{C}>(1+$ i), biaya produksi yang digunakan efisien. di mana $i$ adalah suku bunga. 


\section{HASIL DAN PEMBAHASAN}

\section{Profil Petani Jagung dan Kedelai}

Tabel 1. Profil Petani Jagung dan Kedelai di Kabupaten Jember Tahun 2015

\begin{tabular}{clccc}
\hline \multirow{2}{*}{ No. } & Uraian & \multicolumn{2}{c}{ Rata-rata Usahatani } & \multicolumn{1}{c}{$\begin{array}{c}\text { Rata-rata } \\
\text { Jagung dan Kedelai }\end{array}$} \\
\cline { 3 - 5 } & & Jagung & Kedelai & 0,70 \\
\hline 1 & Luas Lahan (ha) & 0,60 & 0,79 & 46 \\
3 & Umur (th) & 45 & 47 & 8 \\
4 & Pendidikan (th) & 9 & 8 & 23 \\
\hline
\end{tabular}

Sumber: Analisis data primer (2017).

Rata-rata umur petani jagung dan kedelai di Kabupaten Jember adalah 46 tahun. Berdasarkan pendidikan formal yang pernah ditempuh menunjukkan bahwa rata-rata tingkat pendidikan petani

Tingkat dan Perbedaan Nilai Produktivitas Usahatani Jagung dan Kedelai

Tabel 2. Rata-rata Nilai Produktivitas Lahan, Tenaga Kerja dan Biaya per Hektar Usahatani Jagung dan Kedelai di Kabupaten Jember Tahun 2015

\begin{tabular}{clrrr}
\hline \multirow{2}{*}{ No. } & \multirow{2}{*}{ Nilai Produktivitas } & \multicolumn{2}{c}{ Usahatani } & \multirow{2}{*}{ Perbedaan } \\
\cline { 3 - 4 } & & \multicolumn{1}{c}{ Jagung } & Kedelai & \\
\hline 1 & Lahan $(\mathrm{Rp} / \mathrm{ha})$ & $18.227 .753,84$ & $12.924 .009,13$ & $5.303 .744,71$ \\
2 & Tenaga Kerja (Rp/JKP) & $30.303,45$ & $30.662,39$ & $-358,94$ \\
3 & Biaya (Rp/Rp) & 1,49 & 1,37 & 0,12 \\
\hline
\end{tabular}

Sumber: Analis data primer (2017).

Rata-rata nilai produktivitas usahatani jagung lebih tinggi dibandingkan kedelai, dengan nilai perbedaan sebesar Rp 5.303.744,71. Hal ini dikarenakan, nilai produksi yang dihasilkan usahatani jagung lebih tinggi dibandingkan kedelai. Selanjutnya ratarata nilai produktivitas tenaga kerja usahatani jagung relatif lebih rendah dibandingkan kedelai, dengan nilai sebesar 8 tahun atau setingkat SMP. Dalam usahatani jagung dan kedelai ratarata pengalaman petani yaitu sekitar 23 tahun. 
Volume 02, No 02- September 2018

ISSN: 2581-1339 (Print), ISSN: 2615-4862 (Online)

Tabel 3. Hasil Analisis Uji Beda Nilai Produktivitas Usahatani Jagung dan Kedelai

\begin{tabular}{|c|c|c|c|c|c|}
\hline \multirow{2}{*}{ No. } & \multirow{2}{*}{ Nilai Produktivitas } & \multicolumn{2}{|c|}{ Mean } & \multirow{2}{*}{ Perbedaan } & \multirow{2}{*}{$\begin{array}{l}\text { Probabilitas } \\
\text { Signifikansi }\end{array}$} \\
\hline & & Jagung & Kedelai & & \\
\hline 1 & Lahan (Rp/ha) & 18.227 .753 & 12.924 .009 & 5.303 .745 & $0,000^{* * * * *}$ \\
\hline 2 & Tenaga Kerja (Rp/JKP) & 30.303 & 30.662 & 359 & $0,780^{\mathrm{ns}}$ \\
\hline 3 & Biaya $(R p / R p)$ & 1,49 & 1,37 & 0,12 & $0,000^{* * * *}$ \\
\hline
\end{tabular}

Keterangan: Pengujian hipotesis menggunakan uji-z dua arah, di mana ${ }^{* * *}$ menyatakan signifikan, masing-masing pada tingkat kepercayaan 99\%. ns: tidak signifikan pada taraf kepercayaan $90 \%$.

Sumber: Analis data primer (2017).

Terdapat perbedaan yang sangat signifikan pada nilai produktivitas lahan dan biaya produksi antara usahatani jagung dan kedelai, sedangkan nilai produktivitas tanaga kerja menunjukkan tidak ada perbedaan yang signifikan.
Faktor-Faktor Yang Berpengaruh Terhadap Produksi Usahatani Jagung dan Kedelai

Dalam usahatani jagung dan kedelai faktor-faktor yang diduga berpengaruh terhadap nilai produksi berupa luas lahan, nilai benih, nilai pupuk, nilai pestisida, tenaga kerja, manajerial dan komoditas.

Tabel 4. Hasil Analisis Regresi Fungsi Produksi Usahatani Jagung dan Kedelai

\begin{tabular}{lccc}
\hline \multicolumn{1}{c}{ Variabel } & Parameter & Koefisien Regresi & T \\
\hline Konstanta & $\beta_{0}$ & 7,214 & $29,194^{* * * *}$ \\
Luas Lahan $\left(\mathrm{X}_{1}\right)$ & $\beta_{1}$ & 0,684 & $9,634^{* * *}$ \\
Nilai Benih $\left(\mathrm{X}_{2}\right)$ & $\beta_{2}$ & 0,073 & $1,702^{*}$ \\
Nilai Pupuk $\left(\mathrm{X}_{3}\right)$ & $\beta_{3}$ & 0,052 & $2,046^{* * *}$ \\
Nilai Pestisida $\left(\mathrm{X}_{4}\right)$ & $\beta_{4}$ & 0,001 & $0,486^{\mathrm{ns}}$ \\
Tenaga Kerja $\left(\mathrm{X}_{5}\right)$ & $\beta_{5}$ & 0,198 & $6,271^{* * *}$ \\
Manajerial $\left(\mathrm{X}_{6}\right)$ & $\beta_{6}$ & 0,003 & $0,086^{\mathrm{ns}}$ \\
Komoditas & $\delta$ & 0,158 & $2,722^{* * *}$ \\
\hline Std. Error Estimasi & $S e$ & 0,081 & \\
R Square & $R^{2}$ & 0,985 & \\
Adjusted R Square & $\bar{R}^{2}$ & 0,984 & \\
R Berganda & $R$ & 0,993 & \\
F-Ratio & & $1080,620^{* * *}$ & \\
$\sum \beta_{j}$ & & 1,011 & \\
$\mathrm{~N}$ & & 120 & \\
\hline
\end{tabular}

Keterangan: Pengujian hipotesis menggunakan uji-z dua arah, di mana *, ${ }^{* *}$, menyatakan signifikan, masin masing pada tingkat kepercayaan 90\%, 95\%, 99\%. ns: tidak signifikan pada taraf kepercayaan $90 \%$.

Sumber: Analis data primer (2017). 
Berdasarkan hasil analisis regresi fungsi produksi, maka persamaan garis fungsi produksi usahatani jagung dan kedelai dapat dirumuskan sebagai:

$\ln Y=7,214+0,684 \ln X_{1}+0,073 \ln X_{2}+0,052 \ln X_{3}+0,001 \ln X_{4}+0,198 \ln X_{5}+0,003 \ln X_{6}+0,158$ $\ln Y_{(D=1)}=7,372+0,684 \ln X_{1}+0,073 \ln X_{2}+0,052 \ln X_{3}+0,001 \ln X_{4}+0,198 \ln X_{5}+0,003 \ln X_{6}$ $\ln Y_{(D=0)}=7,214+0,684 \ln X_{1}+0,073 \ln X_{2}+0,052 \ln X_{3}+0,001 \ln X_{4}+0,198 \ln X_{5}+0,003 \ln X_{6}$

$Y_{(D=1)}=1.290,81 X_{1}^{0,684} X_{2}^{0,073} X_{3}^{0,052} X_{4}^{0,001} X_{5}^{0,198} X_{6}^{0,003}$ $Y_{(D=0)}=1.358,31 X_{1}^{0,684} X_{2}^{0,073} X_{3}^{0,052} X_{4}^{0,001} X_{5}^{0,198} X_{6}^{0,003}$

Faktor luas lahan, nilai benih, nilai pupuk, nilai pestisida, tenaga kerja, manajerial dan komoditas secara bersama-sama berpengaruh secara signifikan terhadap nilai produksi usahatani jagung dan kedelai. Hal ini dapat dilihat dari nilai F-hitung $(=1080,620)$ yang signifikan pada taraf uji 1\%. Dilihat dari nilai koefisien determinasi $\left(\mathrm{R}^{2}\right)$ yang sebesar 0,985 menunjukkan bahwa variabel bebas yang dimasukkan ke dalam model dapat mengidentifikasikan variasi variabel dependen (nilai produksi) secara baik sekitar 98,5\%. Hanya sekitar 1,5\% yang dijelaskan oleh faktor lain yang tidak masuk ke dalam model di antaranya adalah curah hujan dan iklim.

Apabila dilihat dari nilai koefisien regresi parsial dengan menggunakan fullmodel, maka faktor produksi luas lahan, nilai benih, nilai pupuk, tenaga kerja dan komoditas berpengaruh positif dan signifikan terhadap nilai produksi jagung dan kedelai. Sementara pengaruh dari variabel nilai pestisida dan manajerial berpengaruh tidak signifikan, walaupun juga berpengaruh positif terhadap produksi. Besaran elastisitas menunjukkan besaran return to scale yaitu penjumlahan koefisien regresi dari fungsi produksi Cobb-Douglas. Dengan demikian dapat dinyatakan bahwa fungsi produksi usahatani jagung dan kedelai di Kabupaten Jember Increasing Return to Scale karena jumlah koefisien regresi lebih dari satu, yaitu 1,011. Artinya, proposi penambahan faktor produksi akan proposional dengan penambahan produksi, apabila penggunaan faktor nilai produksi ditambah sebesar $1 \%$, maka nilai produksi akan bertambah $1 \%$. 
Volume 02, No 02- September 2018

ISSN: 2581-1339 (Print), ISSN: 2615-4862 (Online)

\section{Tingkat Keuntungan Usahatani Jagung dan Kedelai}

Tabel 5. Produksi, Biaya dan Keuntungan per Hektar Usahatani Jagung dan Kedelai di Kabupaten Jember Tahun 2015

\begin{tabular}{clrr}
\hline \multirow{2}{*}{ No. } & \multirow{2}{*}{ Uraian } & Usahatani \\
\cline { 3 - 4 } & & 5.003 & \multicolumn{1}{c}{ Kedelai } \\
\hline 1 & Produksi $(\mathrm{kg} / \mathrm{ha})$ & 3.645 & 2.055 \\
2 & Harga $(\mathrm{Rp} / \mathrm{kg})$ & 18.227 .754 & 6.289 \\
3 & Penerimaan $(\mathrm{Rp} / \mathrm{ha})$ & 12.264 .673 & 12.924 .009 \\
4 & Biaya $(\mathrm{R} p / \mathrm{ha})$ & 5.963 .080 & 9.501 .368 \\
5 & Keuntungan $(\mathrm{Rp} / \mathrm{ha})$ & & 3.422 .641 \\
\hline
\end{tabular}

Sumber: Analisis data primer (2017).

Rata-rata keuntungan usahatani jagung sebesar Rp 5.960.080 relatif lebih tinggi dibandingkan kedelai sebesar Rp 3.442.641, dengan nilai perbedaan sekitar 2,5 juta rupiah. Hal ini, menyebabkan para petani kedelai enggan menanam kedelai dan beralih ke komoditas lain terutama jagung. Akibatnya, produksi kedelai di Kabupaten Jember dari tahun ketahun semakin menurun. Oleh karena itu, harus ada peran dari pemerintah
Kabupaten Jember untuk mengatasi hal ini, seperti memberikan bantuan benih unggul, pupuk, modal dan teknologi modern serta menjaga kestabilan harga ketika panen. Hasil uji beda rata-rata sebagimana yang ditunjukkan oleh Tabel 6 bahwa terdapat perbedaan keuntungan yang sangat signifikan pada taraf uji $1 \%$, antara usahatani jagung dan kedelai di Kabupaten Jember.

Tabel 6. Hasil Analisis Uji Beda Keuntungan Usahatani Jagung dan Kedelai

\begin{tabular}{clccc}
\hline & Usahatani & Mean & Perbedaan & Probabilitas Signifikansi \\
\hline 1 & Jagung & 5.963 .080 & 2.540 .439 & $0,000^{* * *}$ \\
2 & Kedelai & 3.422 .641 & & \\
\hline
\end{tabular}

Keterangan: Pengujian hipotesis menggunakan uji-z dua arah, di mana ${ }^{* * *}$ menyatakan signifikan, masing-masing pada tingkat kepercayaan 99\%. ns: tidak signifikan pada taraf kepercayaan $90 \%$.

Sumber: Analis data primer (2017).

Faktor-Faktor Yang Berpengaruh

Terhadap Keuntungan Usahatani Jagung dan Kedelai

Dalam usahatani jagung dan kedelai faktor-faktor yang diduga berpengaruh terhadap keuntungan berupa nilai produksi, biaya sarana produksi, biaya tenaga kerja, biaya sewa lahan dan komoditas. Tingkat keuntungan usahatani jagung dan kedelai diasumsikan dipengaruhi oleh faktor: nilai produksi, biaya sarana produksi, biaya tenaga kerja, biaya sewa dan komoditas untuk membedakan antara 
usahatani jagung dan kedelai. Tabel 7 di bawah mengidikasikan bahwa secara bersama-sama semua faktor keuntungan berpengaruh secara signifikan terhadap keuntungan usahatani jagung dan kedelai. Hal ini dapat dilihat dari nilai F-hitung $(=2860,398) \quad$ yang signifikan secara statistik pada taraf uji $1 \%$. Keseluruhan variabel mempunyai tanda sesuai dengan yang diharapkan secara teoritis, yaitu produksi dan komoditas berpengaruh positif, sedangkan biaya sarana produksi, biaya tenaga kerja dan biaya sewa lahan berpengaruh negatif.

\section{Tabel 7. Hasil Analisis Regresi Fungsi Keuntungan Usahatani Jagung dan Kedelai}

\begin{tabular}{lccc}
\hline \multicolumn{1}{c}{ Variabel } & Parameter & Koefisien Regresi & T \\
\hline Konstanta & $\beta_{0}$ & $-5,753$ & $-30,872^{* * * *}$ \\
Nilai Produksi $\left(\mathrm{X}_{1}\right)$ & $\beta_{1}$ & 3,655 & $41,361^{* * * *}$ \\
Biaya Saprodi $\left(\mathrm{X}_{2}\right)$ & $\beta_{2}$ & $-1,020$ & $-23,233^{* * * *}$ \\
Biaya Tenaga Kerja $\left(\mathrm{X}_{3}\right)$ & $\beta_{3}$ & $-0,590$ & $-17,675^{* * * *}$ \\
Biaya Lian-lain $\left(\mathrm{X}_{4}\right)$ & $\beta_{4}$ & $-1,009$ & $-13,359^{* * * *}$ \\
Komoditas & $\delta$ & 0,174 & $4,702^{* * * *}$ \\
\hline Std. Error Estimasi & $S e$ & 0,073 & \\
R Square & $R^{2}$ & 0,992 & \\
Adjusted R Square & $\bar{R}^{2}$ & 0,992 & \\
R Berganda & $R$ & 0,996 & \\
F-Ratio & & $2860,398^{* * * *}$ & \\
N & & 120 & \\
\hline
\end{tabular}

Keterangan: Pengujian hipotesis menggunakan uji-t dua arah, di mana ${ }^{* * *}$ menyatakan signifikan, masing-masing pada tingkat kepercayaan 90\%, 95\%, 99

Sumber: Analis data primer (2017).

Berdasarkan hasil analisis regresi fungsi keuntungan, maka persamaan garis fungsi keuntungan usahatani jagung dan kedelai dapat dirumuskan:

$\ln Y=-5,753+3,655 \ln X_{1}-1,020 \ln X_{2}-0,590 \ln X_{3}-1,009 \ln X_{4}+0,174 D$ $\ln Y_{(D=1) j \text { jagung }}=-5,579+3,655 \ln X_{1}-1,020 \ln X_{2}-0,590 \ln X_{3}-1,009 \ln X_{4}$ $\ln Y_{(D=0) \text { kedelai }}=-5,753+3,655 \ln X_{1}-1,020 \ln X_{2}-0,590 \ln X_{3}-1,009 \ln X_{4}$

$$
\begin{aligned}
& Y_{(D=1) \text { jagung }}=0,004 X_{1}^{3,655} X_{2}^{-1,020} X_{3}^{-0,590} X_{4}^{-1,009} \\
& Y_{(D=0) \text { kedelai }}=0,003 X_{1}^{3,655} X_{2}^{-1,020} X_{3}^{-0,590} X_{4}^{-1,009}
\end{aligned}
$$

Dilihat nilai koefisien determinasi $\left(\mathrm{R}^{2}\right)$ yang sebesar 0,992 menunjukkan bahwa variabel bebas yang dimasukkan ke dalam model dapat menjelaskan variasi variabel dependen (keuntungan) secara baik sekitar 99,2\%, Hanya 0,8\% yang dijelaskan oleh faktor lain yang tidak masuk ke dalam model. Selanjutnya secara individu hasil pengujian koefisien regresi parsial menggunakan full-model menunjukkan bahwa faktor nilai produksi, biaya saprodi, biaya tenaga kerja, biaya sewa lahan dan komoditas berpengaruh secara signifikan terhadap keuntungan usahatani jagung dan kedelai.

Tingkat dan Perbedaan Efisiensi Penggunaan Biaya Produksi Usahatani Jagung dan Kedelai

Prinsip dari suatu usahatani termasuk usahatani jagung dan kedelai 
Volume 02, No 02- September 2018

ISSN: 2581-1339 (Print), ISSN: 2615-4862 (Online)

adalah menghasilkan produksi yang

dengan melakukan efisiensi dalam

maksimal dengan menekan penggunaan

penggunaan biaya produksi.

biaya yang seminimal mungkin atau

Tabel 8. Efisiensi Penggunaan Biaya Produksi per Hektar Usahatani Jagung dan Kedelai di Kabupaten Jember Tahun 2015

\begin{tabular}{clccc}
\hline \multirow{2}{*}{ No. } & \multicolumn{1}{|}{ Uraian } & \multicolumn{2}{c}{ Usahatani } & \multirow{2}{*}{ Perbedaan } \\
\cline { 3 - 4 } & & Jagung & Kedelai & \\
\hline 1 & Penerimaan (Rp/ha) & 18.227 .754 & 12.924 .009 & 5.303 .745 \\
2 & Biaya Produksi (Rp/ha) & 12.264 .673 & 9.501 .368 & 2.763 .305 \\
3 & Efisiensi (R/C) & 1,49 & 1,37 & 0,12 \\
\hline
\end{tabular}

Sumber: Analisis data primer (2017).

Hasil analisis menunjukkan bahwa nilai $\mathrm{R} / \mathrm{C}$ usahatani jagung dan kedelai yang dihasilkan sebesar 1,49 dan 1,37, mengacu pada Bank Rakyat Indonesia (BRI) dalam menentukan tingkat suku bunga dasar kredit usaha rakyat atau KUR pada tahun 2015 yaitu sebesar 7\% per tahun atau $2,33 \%$ per musim tanam. Maka, besarnya nilai R/C yang diperoleh petani jagung dan kedelai lebih dari 1,023 $(\mathrm{R} / \mathrm{C}>1+\mathrm{i})$. Artinya, setiap biaya yang dikeluarkan untuk usahatani jagung dan kedelai sebesar Rp 1.023.000, maka akan diperoleh penerimaan sekitar 1,49 dan 1,37 juta rupiah. Dengan demikian usahatani jagung dan kedelai di Kabupaten Jember dapat dikatakan efisien dalam penggunaan biaya usahataninya.

Sementara untuk mengetahui perbedaan tingkat efisiensi penggunaan biaya antara usahatani jagung dan kedelai di Kabupaten Jember, ditunjukkan pada Tabel 9.

Tabel 9. Hasil Analisis Uji Beda Efisiensi Penggunaan Biaya Usahatani Jagung dan Kedelai

\begin{tabular}{clccc}
\hline No. & Usahatani & Mean & Perbedaan & Probabilitas Signifikansi \\
\hline 1 & Jagung & 1,487 & 0,121 & $0,000^{* * *}$ \\
2 & Kedelai & 1,366 & & \\
\hline
\end{tabular}

Keterangan: Pengujian hipotesis menggunakan uji-z dua arah, di mana ${ }^{* * *}$ menyatakan signifikan, masing-masing pada tingkat kepercayaan $99 \%$

Sumber: Analis data primer (2017).

Berdasarkan hasil penelitian dapat disimpulkan bahwa, perbandingan antara usahatani jagung dan kedelai menunjukkan adanya perbedaan yang sangat signifikan pada taraf uji $1 \%$. Hal ini dikarenakan rata-rata penggunaan biaya antara usahatani jagung dan kedelai berbeda, sesuai dengan kebutuhan masing-masing jenis usahatani. 


\section{KESIMPULAN}

Berdasarkan perumusan masalah, tujuan penelitian, hipotesis dan hasil penelitian serta pembahasan, maka dapat disimpulkan bahwa: (1) Rata-rata nilai produktivitas (lahan, tenaga kerja dan biaya produksi) usahatani jagung adalah ( $\mathrm{Rp}$ 18.227.753,84/ha; Rp 30.303/JKP; 1,49) dan kedelai $\quad(\operatorname{Rp} \quad 12.924 .009,13 / \mathrm{ha} ; \quad \mathrm{Rp}$ 30.662,39/JKP; 1,37). Nilai produktivitas lahan dan biaya produksi usahatani jagung lebih besar dibandingkan dengan kedelai, secara statistik terdapat perbedaan yang signifikan pada taraf uji $1 \%$. Sedangkan nilai produktivitas tenaga kerja usahatani jagung relatif lebih kecil dibandingkan kedelai, akan tetapi secara statistik tidak berbeda nyata pada taraf kepercayaan 90\%. (2) Faktorfaktor yang berpengaruh signifikan terhadap nilai produksi usahatani jagung dan kedelai adalah luas lahan, benih, pupuk, tenaga kerja dan komoditas, sedangkan faktor pestisida dan manjerial berpengaruh tidak nyata. (3) Usahatani jagung dan kedelai di Kabupaten Jember adalah menguntungkan, dengan ratarata keuntungan sebesar Rp 5.963.080/ha untuk jagung dan $\mathrm{Rp}$ 3.422.641/ha untuk kedelai. Keuntungan usahatani jagung lebih besar dibandingkan dengan kedelai dan secara statistik berbeda nyata pada taraf uji $1 \%$. (4) Keuntungan usahatani jagung dan kedelai secara signifikan dipengaruhi oleh nilai produksi, biaya sarana produksi, biaya tenaga kerja dan biaya lain-lain.

Penggunaan biaya produksi dalam usahatani jagung dan kedelai di Kabupaten Jember adalah efisien dengan nilai $\mathrm{R} / \mathrm{C}=1,49$ untuk jagung dan $\mathrm{R} / \mathrm{C}=1,37$ untuk kedelai. Nilai efisiensi penggunaan biaya usahatani jagung lebih tinggi dibandingkan dengan kedelai dan secara statistik terdapat perbedaan yang signifikan pada taraf uji $1 \%$.

\section{DAFTAR PUSTAKA}

Rahayu, C.D 2011. Analisis Usahatani Kedelai (Studi Kasus di Kecamatan Bangsalsari, Kabupaten Jember). Fakultas Pertanian. Universitas Muhammadiyah Jember. Jember.

Suprapto. 2006. Keunggulan Komperatif dan Dampak Kebijakan Produksi Jagung di Propinsi Jawa Timur. Buletin Penelitian Puslit Universitas Mercubuana. (10): 89-106. Jakarta.

Suryabrata, S. 1983. Metodologi Penelitian. CV. Rajawali Jakarta. Jakarta.

Sutiarso, E. 2010. Analisis Regresi Sederhana. Jurusan Sosial Ekonomi Pertanian. Fakultas Pertanian. Universitas Muhammdiyah Jember. Jember.

Zakaria, Amar K. 2010. Kebijakan Pengembangan Budidaya Kedelai Menuju Swasembada Melalui Partisipasi Petani. http://pse.litbang.deptan.go.id/. Diakses tanggal 15 Desember 2016. 